\title{
ADERINTO Saheed. - Guns and Society in Colonial Nigeria. Firearms, Culture and Public Order
}

\author{
Marc-Antoine Pérouse de Montclos
}

\section{OpenEdition}

Journals

Édition électronique

URL : https://journals.openedition.org/etudesafricaines/30552

DOI : 10.4000/etudesafricaines.30552

ISSN : 1777-5353

\section{Éditeur}

Éditions de l'EHESS

\section{Édition imprimée}

Date de publication : 15 juin 2020

Pagination : 434-436

ISBN : $978-2-7132-2828-5$

ISSN : 0008-0055

\section{Référence électronique}

Marc-Antoine Pérouse de Montclos, « ADERINTo Saheed. - Guns and Society in Colonial Nigeria. Firearms, Culture and Public Order », Cahiers d'études africaines [En ligne], 238 | 2020, mis en ligne le 15 juin 2020, consulté le 04 janvier 2023. URL : http://journals.openedition.org/etudesafricaines/30552 ; DOI : https://doi.org/10.4000/etudesafricaines.30552

Ce document a été généré automatiquement le 4 janvier 2023.

Tous droits réservés 


\title{
ADERINTO Saheed. - Guns and Society in Colonial Nigeria. Firearms, Culture and Public Order
}

\author{
Marc-Antoine Pérouse de Montclos
}

\section{RÉFÉRENCE}

ADERINTO Saheed. - Guns and Society in Colonial Nigeria. Firearms, Culture and Public Order. Bloomington, Indiana University Press, 2018, 336 p., bibl., index.

1 Dans un essai innovant, Saheed Aderinto analyse la diffusion et l'usage des armes à feu du temps de la colonisation au Nigeria. D'après lui, les Britanniques ont développé dans ce pays une "culture du flingue " qui a donné naissance à une véritable "gun society", comme il l'appelle. Autrefois, les armes à feu étaient en effet utilisées pour la traite des esclaves ou l'œuvre de conquête des empires précoloniaux. Mais, selon S. Aderinto, elles sont ensuite devenues un outil indispensable du commerce avec l'arrivée des Britanniques, à tel point que les Nigérians n'ont bientôt plus pu s'en passer. Au passage, souligne l'auteur, un pareil constat remet en cause l'affirmation des historiens selon lesquels la difficulté à obtenir des armes aurait expliqué la faiblesse des tentatives de résistance militaire à la colonisation.

Le cas du Nigeria est assez singulier à cet égard. En Afrique du Sud au XIX ${ }^{\mathrm{e}}$ siècle, les Britanniques avaient entrepris d'enregistrer les armes en circulation afin de pouvoir les confisquer et de désarmer les Africains. Au Nigeria, en revanche, leur objectif aurait plutôt été de générer des revenus en percevant des droits de douane sur les importations de poudre. Les Britanniques ont ainsi laissé les masses paysannes utiliser des fusils de chasse à un coup, les dane guns, qui étaient autrefois réservés aux guerriers, à la noblesse et aux confréries d'initiés. Ceux-ci sont devenus si populaires qu'à partir de 1948, les autorités coloniales ont levé l'obligation de les faire enregistrer. 
Comme en Afrique du Sud, la vente aux particuliers d'armes légales était certes discriminatoire. Seule l'élite occidentalisée et la chefferie traditionnelle étaient, au Nigeria, officiellement autorisées à posséder des armes de précision. Les paysans, eux, devaient se contenter des dane guns, fusils de fabrication artisanale qui, en l'occurrence, étaient fort dangereux car ils avaient souvent tendance à exploser entre les mains de leurs utilisateurs! Quant aux Européens, il leur était beaucoup plus facile d'obtenir légalement des armes à feu. Peu nombreux, ils n'ont cependant pas monté de milices pour aller réprimer les protestations des Africains, à la différence des Français du Cameroun lors du soulèvement de Douala en 1945. Initiés en 1914 par les Britanniques pour repousser une éventuelle tentative d'invasion allemande, les groupes d'autodéfense des Blancs de Lagos, par exemple, n'ont pas connu de suites après la Première Guerre mondiale.

4 Dans le chapitre 5, sans doute le meilleur du livre, S. Aderinto montre plutôt comment la politique du colonisateur a, en fait, contribué à fragiliser l'appareil coercitif de l'État nigérian. Désireux de prévenir d'éventuels soulèvements contre la présence des Européens, le célèbre gouverneur Frederick Lugard avait ainsi interdit aux polices « indigènes » de porter des armes à feu. Les autorités étaient tout aussi réticentes à former la police nationale à l'usage des armes. Résultat, les forces de l'ordre ne savaient pas gérer les mouvements de foule et ont pris pour habitude de tuer des civils en toute impunité. Les autorités ont su masquer leurs bavures à répétition. À partir des années 1920, par exemple, elles ont utilisé des euphémismes pour évoquer des opérations contre-insurrectionnelles autrefois qualifiées "d'expéditions » et désormais désignées sous le nom « d'escortes » ou de « patrouilles».

Comme aujourd'hui, la police nigériane a systématiquement cherché à minimiser le nombre de ses victimes civiles. C'était d'autant plus facile qu'en milieu rural, la brutalité de la répression des violences communautaires ne faisait guère l'objet de recensions dans la presse locale. Plus visibles, ce sont surtout les émeutes en milieu urbain ou ouvrier qui ont fait l'objet d'enquêtes officielles. Devenue un symbole de la lutte des nationalistes pour l'indépendance, la sanglante répression de la grève des mineurs de charbon d'Enugu en 1949 allait enfin pousser les autorités à former les forces de l'ordre à la gestion des manifestations de rues. Les autorités ont d'ailleurs vanté le succès de leurs efforts de professionnalisation quand la police intervint dans la région Nord sans tuer personne au milieu des troubles qui firent officiellement 36 morts à Kano en 1953, en majorité des Nigérians venus du Sud.

6 Le livre de S. Aderinto apporte ainsi un éclairage inédit sur certains aspects de la politique coloniale. Pour autant, il comporte aussi des lacunes et des contradictions. Essentiellement préoccupé par les agissements du colonisateur, S. Aderinto ne dit par exemple rien des sources d'approvisionnement locales de fusils de fabrication artisanale, notamment par le biais des forgerons d'Awka en pays ibo. L'auteur ne craint pas non plus la contradiction lorsqu'il reproche tout à la fois aux Britanniques d'avoir popularisé une «culture du flingue » et, de façon discriminante, limité aux Blancs le droit de posséder des armes à feu plus sophistiquées. Dans sa conclusion, S. Aderinto reconnaît d'ailleurs bien tardivement que, pour préserver la paix publique et maintenir l'ordre, la politique coloniale a finalement eu le mérite d'empêcher les masses nigérianes d'avoir accès aux armes les plus létales, ce qui a peut-être permis de limiter la diffusion de la criminalité et des violences communautaires. 
7 À l'analyse, il s'avère que l'auteur n'est pas non plus très convaincant quand il soutient que les Britanniques auraient autorisé la diffusion des dane guns à des fins lucratives. En réalité, les revenus des droits de douane sur les importations de munitions sont restés dérisoires à l'échelle du budget de la colonie. Il est d'ailleurs possible que les montants en jeu aient en réalité décliné : la traite des esclaves avait été beaucoup plus propice au commerce de poudre et d'explosifs, avec des importations qui, en Afrique de l'Ouest, avaient atteint un record de 2 millions de livres en 1790 selon des chiffres cités par S. Aderinto.

8 De fait, les tentatives de quantification des phénomènes qu'étudie l'auteur constituent certainement le point le plus faible du livre. L'auteur affirme par exemple que, toutes proportions gardées, jamais autant de Nigérians ont été en mesure de posséder des armes légalement ou illégalement que pendant la période coloniale, de 1900 à 1960. Relativement à la croissance de la population, un tel constat aurait pourtant pu être nuancé si l'on en juge par les estimations des historiens à propos du commerce des armes du temps de la traite des esclaves et par l'absence de données quantitatives à ce sujet pendant les périodes de dictature militaire après l'indépendance. 